\title{
Interleukin 10 And 18 Levels in Essential Hypertensive
}

\section{${ }^{* 1}$ ODEWUSI, OO; ${ }^{2}$ OSADOLOR, HB}

\author{
${ }^{1}$ Department of medical laboratory science, College of Medicine and Health Sciences, Afe Babalola University, Ado Ekiti, Nigeria \\ ${ }^{2}$ Department of medical laboratory science, College of Medical Sciences, University of Benin, Benin City, Edo State, Nigeria \\ *Corresponding Author Email: yinksdadon@yahoo.com
}

\begin{abstract}
The mechanism underlying a sustained blood pressure elevation and its sequelae on the inflammatory cascades have not been totally unraveled. This research was, in addition to body mass index (BMI), systolic and diastolic blood pressure (SBP and DBP) therefore, primarily set to assess the levels of; interleukins -18 and 10 (Il-18 and Il-10) as markers of pro and anti-inflammation. The study included 317 subjects- 100 untreated with essential hypertension and currently not on drugs, 114 with essential hypertension and on antihypertensive drugs together with DASH diets and lifestyle modifications. The remaining were 103 control subjects with normal blood pressure. All parameters were assessed in treated and untreated hypertensive patients relative to apparently healthy subjects. Secondarily, it was also designed to assess the effect of treatment, gender and age on all estimated parameters. The results were subjected to statistical analysis using SPSS 21. The Student's t test was used in comparing means. Values were Significant at P<0.05. SBP, DBP, Il-18, were significantly increased while IL10 was significantly decreased in both treated and untreated hypertensive compared to control. BMI was insignificantly increased in treated hypertensive but significantly increased in untreated hypertensive relative to control. SBP, DBP, Il 18, were significantly lower while IL10 was significantly higher in treated hypertensive compared with untreated hypertensive. It was discovered that inflammation is a hallmark in hypertensive can be significantly reversed through the administration of antihypertensive drugs, diets and a strict adherence to healthy lifestyle modifications. These findings could help to design better interventions and get better outcomes for essential hypertensive.
\end{abstract}

\section{DOI: $\underline{\text { https://dx.doi.org/10.4314/jasem.v23i5.7 }}$}

Copyright: Copyright $\odot 2019$ Odewusi and Osadolor. This is an open access article distributed under the Creative Commons Attribution License (CCL), which permits unrestricted use, distribution, and reproduction in any medium, provided the original work is properly cited.

Dates: Received: 19 October 2018; Revised: 22 March 2019; Accepted 13 April 2019

Keywords: Essential hypertension, interleukins, Anti-inflammatory, pro-inflammatory

Hypertension or high blood pressure is a global problem that affects approximately $15-20 \%$ of all adults (Wang et al., 2008). Hypertension is known as the silent killer as it shows no signs and symptoms. Even though it is simple to diagnose and usually can be controlled by healthy diet, regular exercise, medications or a combination of these, hypertension if unattended to will cause grave manifestations (Yeh et al., 2009). Hypertension is associated with cardiovascular disease, insulin resistance, carbohydrate intolerance, hyperuricaemia and atherosclerosis (Yeh et al., 2009). It also affects the structures and functions of small vascular arteries, arterioles and other blood vessels and can cause damage at variable rate to various target organs including kidney, brain and eye, related with the end stage of renal disease and to be the cause of stroke (Escobales et al., 2005; Lee et al., 2010). It is associated with the alterations in the blood vessels wall that is affecting the endothelium, the media and the adventitia; the alteration in the media leads to remodelling of the vessel wall (Escobales et al., 2005). Patients with hypertension may die prematurely with the most common cause of death being heart disease, while strokes and renal failures are also frequent, particularly in those with significant retinopathy (Lee et al., 2010).

Interleukin -18 is a pleiotropic pro-inflammatory cytokine and plays a central role in the inflammatory cascade (Dinarello and Fantuzzi, 2003). Cells known to express interleukin 18 include macrophages, Kupffer cells, keratinocytes, and glucocorticoidssecreting adrenal cortex cells (Blankenberg et al., 2002). It is a member of the interleukin 1 super family, has several biological activities that initiate and promote host defence and inflammation (Dinarello and Fantuzzi, 2003). It is biologically and structurally related to interleukin 1 beta (Dinarello and Fantuzzi, 2003). In contrast to most other cytokines, but in a similar way to IL-1b, IL-18 is expressed as a precursor, pro-IL18, which is not active until cleaved by the enzyme caspase- 1 . Caspase- 1 itself exists as an inactive precursor which requires the assembly of multi-unit complexes, known as inflammasomes, to be activated (Nakanishi et al., 2001). Experimental research have shown that interleukin 18 enhances atherosclerosis through release of interferon gamma (Whitman et al., 2002) and induces expression of inflammatory cytokine IL- 6 in the vascular endothelial 
and smooth muscle cells (Gerdes et al., 2002).These downstream cytokines are associated with highly pro inflammatory T-helper 1 (Th1)- and T-helper 17 (Th17)-type immune responses and there is evidence to suggest that Th1 and Th17 cells play a major role in hypertension It has been proposed that the vascular systemic inflammation produced by adipose tissues contributes to the development of hypertension (Dinarello and Fantuzzi., 2003). Interleukin 18 provides powerful information on future fatal cardiovascular events across the entire spectrum of patients with stable coronary artery disease (CAD) and patients with unstable CAD (Blankenberg et al., 2002). IL-10 on the other hand is an anti-inflammatory cytokine that is produced by activated T cells, B cells, keratinocytes, and monocytes (Howard et al., 1992). Interleukin 10 (IL-10) is a Type II cytokine in a family that includes: IL19, IL-20, IL-22, IL-26, and IL-29.

These cytokines have similar gene organisation and bind to receptors of similar structure (Akuffo et al., 1999). In general, the main biological functions of IL10 are to decrease or regulate the inflammatory response produced by dendritic cells and macrophage (Akuffo et al., 1999). Surprisingly, IL-10 is not always inhibitory, it can also promote B-cell activation and stimulate NK-cell proliferation. When IL-10 is produced and secreted, it acts specifically on the IL-10 receptor, the structure of which consists of two subunits; IL-10 receptor 1 and IL-10 receptor 2. IL-10 is highly secreted in mucosal tissues, such as the gut and the lung, where unwanted or uncontrolled immune responses can be very damaging (Pestka et al., 2004).

As hypertension has been described to be a manifestation of immunological and other factors (Aristides and Rayaz, 2007), this research was, in addition to body mass index (BMI), systolic and diastolic blood pressure (SBP and DBP) therefore, primarily set to assess the levels of interleukins 10 and 18 (Il- 10 and18) as anti and pro inflammatory markers in treated and untreated hypertensive patients relative to apparently healthy subjects.

\section{MATERIALS AND METHODS}

Study Design: A cross-sectional design using a stratified random sampling method was used. Stratification was by age and therapy.

Study Area The study area is Ado Ekiti and its immediate environs.

Sample Size. The minimum sample size (N) was calculated to be 308 by single proportion formula, (Araoye, 2004) based on a prevalence of $28.9 \%$.

$$
N=Z^{2} p \frac{(1-p)}{D^{2}}
$$

Where; $\mathrm{Z}=$ confidence level at $95 \%, \mathrm{~N}=$ Minimum sample size, $\mathrm{D}=$ desired precision $=0.05, \mathrm{P}=$ estimated prevalence of essential hypertension in Ado-Ekiti. Thus,

$$
N=(1.98)^{2} \cdot 0.289 \frac{(1-0.289)}{(0.05)^{2}}=308
$$

Therefore to make up for possible drop outs and outliers, a total of three hundred and seventeen (317) subjects were investigated.

Inclusion And Exclusion Criteria: Men and women who are hypertensive whether on therapy or not partook in the study. Inclusion was based on the cutoff of at least $140 \mathrm{mmHg}$ systolic and or $90 \mathrm{mmHg}$ diastolic Blood pressure while Subjects below the age of 18 years, pregnant women, nursing mothers, diabetes mellitus subject, chronic kidney disease, and sufferers of other disease conditions were excluded.

Grouping: Treated hypertensives are those that have been diagnosed of Hypertension and have been on treatment for at least 3months. Treatment being the administration of antihypertensive drugs alongside DASH diets and lifestyle modifications. Untreated hypertensives are those that have just been newly diagnosed of having essential hypertension or a known hypertensive that have not been on treatment for at least 3 months. Ethical approval was sought for, from Afe Babalola University Teaching Hospital, Ado Ekiti, Ekiti state.

Sample Collection: Venous blood sample of about $5 \mathrm{ml}$ was collected from the cubital fossa using a $22 \mathrm{G}$ needle and syringe and dispensed into a plain bottle (non-anticoagulant bottle). The blood was allowed to clot and centrifuged at 12000 rpm for 5 minutes to separate the serum from cells. The serum samples were stored at temperature of -20 degree Celsius for a maximum of 5 days before assayed for interleukins 10 and 18 .

Determination of Basal metabolic rate (BMI): Anthropometric data which include body weight and height were obtained using bathroom scales and a height gauge respectively. The height (m) and weight $(\mathrm{Kg})$ measurements were then used to calculate the body mass index (BMI) using the formula

$$
B M I=\frac{\text { weight }}{(\text { height })^{2}}
$$


Determination of Blood pressure (Systolic and diastolic) readings was taken from the non-dominant arm using a digital sphygmomanometer (Omros, Japan) according to manufacturer's guidelines. Systolic blood pressure (SBP) and diastolic blood pressure (DBP) were displayed digitally.

Procedures and quality control measures for blood pressure determination: Before taking measurements:

i. The subjects were instructed to abstain from exercise, smoke or consumption of foods or drinks containing caffeine (such as tea or coffee) for at least 30 minutes before measurement

ii. ii. The subjects were made to wear loose-fitting and comfortable clothes,

iii. Rest and relax for 5 minutes without any distractions (such as watching television).

iv. A stable table and chair of appropriate height was chosen

v. The subject were comfortably seated and relaxed with their back supported

vi. The arm was supported on a tabletop at an even level with your heart

vii. The feet were on the floor and it was made sure that the legs were not crossed

Measuring Blood Pressure:

i. The sleeve was rolled up to expose the upper arm and the cuff was wrapped around it

ii. The cuff on the exposed arm was placed $2 \mathrm{~cm}$ (approximately two finger-breadths) above the elbow. iii The tubing was placed at the centre of the arm facing the front, the sensor was correctly placed and the end of the cuff was pulled so that it was wrapped evenly and firmly around the arm.

iv It was checked that the tightness of the cuff is appropriate so that when the cuff inflates it should not cause any painful sensation

v. Once the start button is pressed the cuff inflates to a maximum, then automatically slowly deflate. Once the measurement is completed, readings of the systolic and diastolic blood pressure were displayed on the digital panel

vi. The reading of each measurement was then recorded

vii. After completing each measurement, the cuff was released completely

viii. Readings were taken in duplicates at an interval of at least one minute between readings

ix. The average value of the two readings was calculated. This value is taken to be the diastolic blood pressure. In case of the two readings on a subject differing by more than $5 \mathrm{mmHg}$, one additional reading was obtained before the average was taken. c. Interleukins 18 and 10 were estimated using ELISA based kits.
Assay procedure: 1. $100 \mu \mathrm{L}$ of each standard and sample was added into appropriate wells. The plate was covered well and Incubated for 2.5 hours at room temperature with gentle shaking. All materials and prepared reagents were equilibrated to room temperature $\left(18-25^{\circ} \mathrm{C}\right)$ prior to use.

2. The Solution was discarded and washed 4 times with $1 \mathrm{X}$ Wash Solution. It was washed by filling each well with $1 \mathrm{X}$ Wash Solution $(300 \mu \mathrm{L})$ autowasher. After the last wash, removal of any remaining Wash Buffer was done by aspiration.

3 . The $100 \mu$ Lof $1 X$ Biotinylated IL-10 or 18 Detection Antibody was added to each well to each well. It was incubated for 1 hour at room temperature with gentle shaking.

4. The solution was discarded. The wash as in step 2 was repeated.

$5.100 \mu \mathrm{L}$ of $1 \mathrm{X}$ HRP-Streptavidin solution was added to each well and then incubated for 45 minutes at room temperature with gentle shaking.

6 . The solution was discarded .The wash step as in step 2 was repeated.

$7.100 \mu \mathrm{L}$ of TMB One-Step Substrate Reagent was added to each well and incubated for 30 minutes at room temperature in the dark with gentle shaking.

8. $50 \mu \mathrm{L}$ of Stop Solution was added to each well. The absorbance was read at $450 \mathrm{~nm}$ wavelength immediately. The concentration of IL-10or 18 for each sample well was computed and displayed on the digital monitor.

Statistical Analysis. Results obtained were subjected to statistical analysis using SPSS (version 21.0 software, SPSS Inc. Chicago, Illinois, USA). All parameters were expressed as mean \pm SD. The Student's t test was the tool of choice in comparing means. Values were statistically significant at $\mathrm{p} \leq 0.05$.

\section{RESULTS AND DISCUSSION}

Table 1. Body mass index (BMI), Systolic and Diastolic blood pressure (SBP and DBP), Interleukin 18 (Il 18), in treated hypertensive when compared with control (Table 4.1). BMI was insignificantly higher while blood pressure (SBP and DBP) Il 18 were significantly higher while Il10 was significantly lower in treated hypertensive compared with control. Hypertension (HTN) is a sustained elevation of resting systolic BP $(\geq 120 \mathrm{~mm} \mathrm{Hg})$, diastolic $\mathrm{BP}(\geq 90 \mathrm{~mm} \mathrm{Hg})$, or both (AHA, 2014). Essential hypertension is the result of a complex interplay between multiple regulatory systems which are themselves influenced by a multitude of genetic and environmental factors (McCallum et al., 2015), resulting in a sustained blood pressure elevation to which no specific cause can be adduced. The excessive high pressure on artery walls caused by HTN can damage blood vessels along with organ function. This increases the risk for developing 
several health conditions including heart attack, stroke, chronic heart failure (CHF), and kidney disease (Saseen et al., 2014).

Table 1 BMI, blood pressure, Il 18 and Il 10 in treated hypertensive compared with control

\begin{tabular}{llll}
\hline $\begin{array}{l}\text { Variables } \\
\text { (mean }=\mathrm{SD})\end{array}$ & $\begin{array}{l}\text { Hypertensives } \\
\text { on treatment } \\
\text { (n=114) }\end{array}$ & $\begin{array}{l}\text { Control } \\
\text { (n=103) }\end{array}$ & P value \\
\hline $\mathrm{BMI}$ & $25.03 \pm 3.90$ & $24.29 \pm 3.43$ & 0.221 \\
$\mathrm{SBP}(\mathrm{mmHg})$ & $151.89 \pm 10.08$ & $115.00 \pm 6.25$ & .000 \\
$\mathrm{DBP}(\mathrm{mmHg})$ & $95.05 \pm 4.71$ & $74.12 \pm 2.76$ & .000 \\
II $18(\mathrm{Pg} / \mathrm{ml})$ & $294.25 \pm 539.03$ & $82.16 \pm 118.95$ & .000 \\
IL $10(\mathrm{pg} / \mathrm{ml})$ & $87.19 \pm 35.15$ & $137.68 \pm 32.84$ & .000 \\
\hline
\end{tabular}

Table 2 BMI, blood pressure, Il 18 and Il 10, in untreated hypertensive when compared with control. BMI, blood pressure and Il 18 were significantly higher while Il 10 was significantly lower in untreated hypertensive compared with control.

Table 2 BMI, blood pressure, IL 18 and IL 10 in untreated hypertensive compared with control

\begin{tabular}{|c|c|c|c|}
\hline $\begin{array}{l}\text { Variables } \\
(\text { mean } \pm \text { SD) }\end{array}$ & $\begin{array}{l}\text { Untreated } \\
\text { bypertensixes }(n=100)\end{array}$ & Control (n=103) & $P$ value \\
\hline $\begin{array}{l}\text { BMI } \\
\text { SBP( }(\mathrm{mmHg})\end{array}$ & $\begin{array}{l}25.99 \pm 2.09 \\
156.01 \pm 3.99\end{array}$ & $\begin{array}{l}24.29 \\
115.00\end{array}$ & $\begin{array}{l}.000 \\
.000\end{array}$ \\
\hline $\mathrm{DBP}(\mathrm{mmHg})$ & $99.46 \pm 5.51$ & 74.12 & .000 \\
\hline $\begin{array}{l}\text { IL } 18(\mathrm{Pg} / \mathrm{ml}) \\
\text { IL } 10(\mathrm{pg} / \mathrm{ml})\end{array}$ & $\begin{array}{l}596.22 \pm 599.13 \\
44.97 \pm 23.22\end{array}$ & $\begin{array}{l}82.16 \pm 118.95 \\
137.68 \pm 32.84\end{array}$ & $\begin{array}{l}.000 \\
.000\end{array}$ \\
\hline
\end{tabular}

Table 3 BMI, blood pressure, Il 18, in treated compared with untreated hypertensive. BMI and Il 10 was insignificantly lower while blood pressure (SBP and DBP), Il 18, in treated hypertensive were significantly higher when compared with control.

Table 3. BMI was insignificantly higher, blood pressure, Il 18 and IL 10 in treated hypertensive compared with untreated hypertensive

\begin{tabular}{lccc}
\hline $\begin{array}{l}\text { Variables } \\
\text { (mean } \pm \text { SD) }\end{array}$ & $\begin{array}{l}\text { Hypertensixes on } \\
\text { treatment }(\mathrm{n}=114)\end{array}$ & $\begin{array}{c}\text { Untreated } \\
\text { bveertensixes }(\mathrm{n}=103)\end{array}$ & P value \\
\hline $\mathrm{BMI}$ & $25.03 \pm 3.90$ & $25.99 \pm 2.09$ & .092 \\
$\mathrm{SBP}(\mathrm{mmHg})$ & $151.89 \pm 10.08$ & $156.01 \pm 3.99$ & .000 \\
$\mathrm{DBP}(\mathrm{mmHg})$ & $95.05 \pm 4.71$ & $99.46 \pm 5.51$ & .000 \\
IL $18 \mathrm{Pg} / \mathrm{ml}$ & $294.25 \pm 539.03$ & $596.22 \pm 599.13$ & .000 \\
IL10 $(\mathrm{pg} / \mathrm{ml})$ & $87.04 \pm 37.69$ & $44.97 \pm 23.22$ & .000 \\
\hline
\end{tabular}

Figure 1 and 2. IL18 and IL10 levels according to age groups in untreated essential hypertensive. IL10 shows a pattern of reduction with advancement in age. While interleukin 18 shows a pattern of increase with advancement in age till the fifties, after then a nosedive in concentration. The Systolic blood pressure (SBP) is that due to the pumping of the heart while the diastolic blood pressure (DBP) is the measurement of force per unit area as the heart relaxes to allow the blood to flow into it (Mancia et al., 2013). In this research, the systolic and diastolic blood pressure in both treated and untreated hypertensive were found to be significantly higher than in control. There was also a significant reduction in the SBP and DBP in treated hypertensive when compared with untreated hypertensive. This findings partially agree with the works of Svensson et al., (2004) where Systolic BP (SBP) was significantly higher in hypertensive patients on treatment as compared to controls but did not differ with regard to diastolic BP. It however totally agrees with the works of Diego et al., (2017) and Norbert et al., (2017).

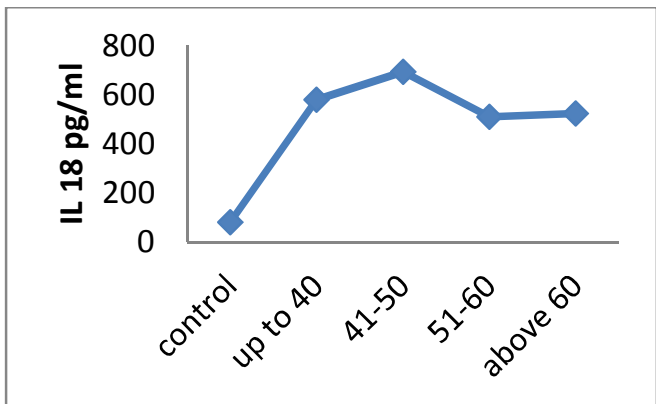

Fig 1. IL18 levels according to age groups in untreated essential hypertensive

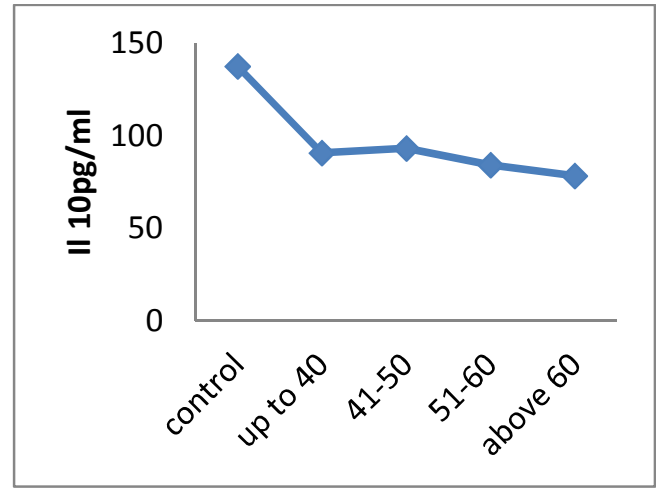

Fig 2. IL10 levels according to age groups in untreated essential hypertensive

Probing Further, a more critical look at this finding shows that classical treatment with drugs, DASH diets and lifestyle modifications was able to bring both the diastolic and systolic blood pressure nearer towards the internationally accepted values seen in controls or, that treatment was effective enough to bring about the alleviation of a severe case to a moderate one. According to one review published in 2003, a reduction of the blood pressure by $5 \mathrm{mmHg}$ can decrease the risk of stroke by $34 \%$, of ischaemic heart disease by 21\%, and reduce the likelihood of dementia, heart failure, and mortality from cardiovascular diseases (Law et al., 2003). It should however be recalled that the essence of treatment is to close the gap in the levels of parameters seen in hypertensive and bring it towards that seen in controls. 
Body mass index (BMI) is a measure of weight adjusted for height, calculated as weight in kilograms divided by the square of height in meters $\left(\mathrm{kg} / \mathrm{m}^{2}\right)$. In this research, the BMI in treated hypertensive was found to be insignificantly higher while that seen in untreated hypertensive was significantly higher when both were compared with that seen in control. Similarly, there was a insignificant variation when the BMI seen in untreated hypertensive was compared with that seen in treated hypertensive. This findings partially agrees with the works of Azantsa et al., (2010); Zhang et al., (2016) and Norbert et al., 2017, where body mass index was seen to be significantly higher in hypertensive, whether treated or untreated, when compared to control. As being overweight has been described as a risk factor for the development and progression of hypertension (Poulter et al., 2015), it would just be wise that weight shedding as a form of lifestyle change and medications will lower blood pressure and decrease the risk of health complications (NHLBI, 2015)

Interleukin 18 is described as a member of interleukin 1 cytokine superfamily, it regulates innate and acquired immune response (Alastair et al., 2003). In a few words interleukin 18 is a common participant in the inflammation cascade and has been known to be pro inflammatory in nature. Serum interleukin 18 was significantly higher in treated and untreated hypertensive when compared with control. Furthermore, there was also a significant increase in untreated hypertensive when compared with treated hypertensive. This agrees with the works of hung et al. (2005) and Luc et al. (2013) where IL-18 and other pro inflammatory cytokines are significantly correlated with hypertension as there was a significant correlation between systolic blood pressure and serum interleukin-18 in both treated and untreated hypertensives. Rabkin in 2009 also elucidated on the role of interleukin 18 on the promotion of vascular abnormalties in hypertension. The pattern of increase in serum IL18 is consistent with advancement in age. Interleukin 10 (IL-10) is a potent anti-inflammatory cytokine that plays a crucial, and often essential, role in preventing inflammatory and autoimmune pathologies (Kuhn et al., 1993; Sabat et al., 2010). In this research, it was seen that interleukin10 level was significantly lower in both treated and untreated hypertensives relative to control, a finding that supports the notion as stated by Lima et al. (2016) where IL10 was said to possess anti pressor activities in mice. It was also observed that IL10 was significantly lower in untreated when compared with treated hypertensive, bringing up a insinuation whether IL10 could be of benefit not only in diagnostic and prognostic but also in therapeutic terms. A pattern of decrease in interleukin 10 was seen with progression in age. There is a speculation to these findings, as IL10 is mostly, if not wholly antiinflammatory in action, Susceptibility to inflammation will be more likely in hypertensive and with advancement in age, hypertensive control in the elderly could be more difficult as a result of lower levels of down regulators of inflammation activation, such as interleukin10 (IL-10). There may therefore be unrestrained limit for inflammasomes drive for inflammation and consequent increased potential for structural damage.

Conclusion: This research found out that accelerated inflammation could be an hallmark of hypertension but could likely be reversed by treatment, through lifestyle and diet modifications and antihypertensive drugs. Lastly, this research ventured into and discovered that the efficacy of treatment on hypertension is incontrovertible. It also confirmed that medication and dash diet could alleviate the inflammatory undertones or manifestations of essential hypertension.

\section{REFERENCES}

Azantsa K; Yangoua, M; Ngondi, J and Julius, E (2010). The effect of body weight on the incidence and prevalence of hypertension in Yaoundé. Journal of Diabetes and Endocrinology. 1:006-012.

Akuffo, H; Alexis, A; Eidsmo, L; Saed, A; Nylén, S; Maasho, K (1999).Natural killer cells in crossregulation of IL-12 by IL-10 in Leishmania antigenstimulated blood donor cells. Clin Exp Immunol. 117(3):529-34

Diego, G; Juliano, C; Luiz, C; Gabriel, G; Raphael, M (2017). Relationship between Resting Heart Rate, Blood Pressure and Pulse Pressure in Adolescents. Arq Bras Cardiology. 108(5):405-410.

Blankenberg, S; Tiret, L; Bickel, C; Peetz, D and Cambien, F (2002). Interleukin 18 is a strong predictor cardiovascular death in unstable and stable angina. Circulation; 106:24-30.

Dinarello, C and Fantuzzi, G (2003). Interleukin-18 and Host Defence against Infection. Journal of Infection. 187(2):370-384.

Escobales, N and Maria, J (2005). Oxidative-Nitrosative Stress in Hypertension. Current Vascular Pharmacology. 3 (3): 231-246.

Gerdes, N; Sukhova, GK; Libby, P; Reynolds, RS and Young, JL (2002). Expression of interleukin 18 and functional IL-18 receptor on human vascular 
endothelial cells, smooth muscle Journal Exp. Medicine; 195:245-257

Howard, SC; Jones, DP; Pui, C (2011). "The Tumour Lysis Syndrome. The New England Journal of Medicine. 364 (19): 1844-1854

Hung, J; McQuillan, B; Chapman, C; Thompson, P; Beilby J (2005). Elevated interleukin-18 levels associated with the metabolic syndrome independent of obesity and insulin resistance. Arteriosclerosis thrombosis vascular biology. Journal of medicine. 25: $1268-1273$.

Kuhn, R; Lohler, J; Rennick, D; Rajewsky, K; Muller, W (1993). Interleukin-10-deficient mice develop chronic enterocolitis. Cell. 75:263-74.

Law, M; Wald, N; Morris, J; Wald, M (2003). "Lowering blood pressure to prevent myocardial infarction and stroke: a new preventive strategy" (PDF). Health Technol Assess. 7 (31): 1-94. PMID 14604498. doi:10.3310/hta7310.

Lee, JK; Kim, SH; Lewis, EC; Azam, T; Reznikov, LL; Dinarello, CA (2004). Differences in signaling pathways by IL-1beta and IL-18. Proc Natl Acad Sci USA 101(23):8815-20

doi:10.1073/pnas.0402800101

Lima, VV; Zemse, SM; Chiao C; Bomfim GF; .Tostes, RC; Webb, RC; Giachini, FR(2016). Interleukin-10 limits increased blood pressure and vascular RhoA/Rho-kinase signaling in angiotensin IIinfused mice. Life Sciences. 145 137-143

Luc, G; Bard, JM; Juhan-Vague, I (2003). "C-reactive protein, interleukin-6, and fibrinogen as predictors of coronary heart disease: the PRIME Study," Arteriosclerosis, Thrombosis, and Vascular Biology 23 (7), pp. 1255-1261.

McCallum, L; Lip, S; and Padmanabhan, S (2015). The hidden hand of chloride in hyper-tension; Pflugers Arch 467(3): 595-603. doi: 10.1007/s00424-0151690-8

Nakanishi, K; Yoshoimoto, T; Tsutsui, H; Okamura, H (2001). Interleukin 18 is a unique cytokine that stimulates both Th1 and Th2 responses depending on its cytokines. Cytokines growth factor review. Journal of medicine. 12: 53-72.

National Heart, Lung, and Blood Institute. "How Is High Blood Pressure Treated?" 10 September 201. Accessed10/10/2017.
Norbert, U; Romokere, A; Odia, J (2017). Prevalence and Determinants of Left Ventricular Geometric and Functional Abnormalities in Asymptomatic Hypertensive Adults at a Tertiary Hospital, SouthSouthern Nigeria. International Journal of Internal Medicine. 6(1): 16-26.

Poulter, NR; Prabhakaran, D; Caulfield, M (2017). Associations of blood pressure with geographical latitude, solar radiation, and ambient temperature: results from the Chilean health survey, 2009-2010 American journal of epidemiology. 183 (11); 107173

Sabat, R; Grütz, G; Warszawska, K; Kirsch, S; Witte, E; Wolk, K; Geginet. J (2010). Biology ointerleukin10. Cytokine Growth Factor Rev. 21(5):331-44.

Svensson, P; de Faire, U; Niklasson, U; and Ostergren J (2004). Office blood pressure underestimates ambulatory blood pressure in peripheral arterial disease in comparison to healthy controls. Journal of Human Hypertension, 18:193-200.

Wang, N; Young, J; Meoni, L; Ford, D; Erlinger, T; Klag, M (2008). Arch International Medicine. 168(6):643648.

Whitman, SC; Ravisankar, P and Daugherty, A (2002). Interleukin-18 enhances atherosclerosis in apolipoprotein E (-/-)mice through release of interferon gamma. Circulation Res.; 90 E34-38.

Mancia, G; Fagard, R; Narkiewicz, K; Redón, J; Zanchetti, A; Böhm, M and Christiaens, T (2013) $\mathrm{ESH} / \mathrm{ESC}$ Guidelines for the management of arterial hypertension: the Task Force for the management of arterial hypertension of the European Society of Hypertension (ESH) and of the European Society of Cardiology (ESC). Journal of Hypertension. 31(7) :1281-1357.

Yeh, E and Bickford, C (2009). Cardiovascular complication of cancer therapy. Journal of American College Cardiology. 53(24):2231-2247.

Zhang, T; Zhang, H; Li Y; Sun, D; Li, S; Fernandez, C; Qi L; Harville, E; Bazzano, L; Jiang, H; Xue. F and Chen. W(2016). Temporal Relationship between Childhood Body Mass Index and Insulin and Its Impact on Adult Hypertension. The Bogalusa Heart Study Hypertension. 68:818- 823. 